\title{
Evaluation of the effectiveness of Ampicillin and Lactobacillus casei rhamnosus treatment in cases of preterm premature rupture of membranes remote from term
}

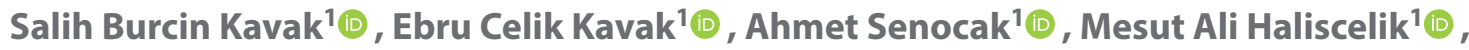 \\ Bunyamin Cim $^{1}[$, Ekrem Sapmazº
}

${ }^{1}$ Firat University, School of Medicine, Department of Obstetrics and Gynecology, Elazig, Turkey

${ }^{2}$ Adana Numune Training and Research Hospital, Department of Obstetrics and Gynecology, Adana, Turkey

\begin{abstract}
Objectives: Preterm premature rupture of membranes (PPROM) remote from term is an important obstetric cause of maternal and fetal adverse outcomes. The aim of our study is to examine the efficacy of ampicillin and Lactobacillus casei rhamnosus treatment in cases of PPROM remote from term.

Material and methods: The study was carried out by examining the results of cases who were given Ampicillin and Lactobacillus casei rhamnosus treatment. The patients were divided into two groups. Group 1 who didn't develop clinical chorioamnionitis and Group 2 who developed clinical chorioamnionitis. Obstetric characteristics, neonatal outcomes, adverse events were recorded.

Results: A total of 46 pregnant women, 40 in Group 1 and six in Group 2, were included in the study. The frequency of clinical chorioamnionitis developing during the treatment was found to be $13.0 \%$. Mean gestational age at diagnosis was $28.43 \pm 2.38$ and $28.17 \pm 1.33$ for Groups 1 and Group 2, respectively. Mean gestational age at the time of delivery was $32.38 \pm 2.0731 .33 \pm 1.63$ for Group 1 and Group 2, respectively. The mean latency period for Group 1 and Group 2 was $27.45 \pm 1.71$ days, $23.66 \pm 4.53$, respectively. Sepsis developed in six newborns $(15 \%)$ in Group 1, while it developed in three newborns (50\%) in Group 2. While $90 \%$ of the babies in Group 1 were discharged from the hospital, this rate was $66.7 \%$ in Group 2.

Conclusions: Ampicillin + Lactobacillus casei rhamnosus is an effective treatment method in PPROM cases and positively affects perinatal outcomes.
\end{abstract}

Key words: preterm premature rupture of membranes; ampicillin; L. casei rhamnosus; clinical chorioamnionitis

Ginekologia Polska 2022; 93, 6: 482-488

\section{INTRODUCTION}

Preterm premature rupture of membranes (PPROM) is the rupture of membranes developing without uterine activity prior to the $37^{\text {th }}$ week of gestation. PPROM remote from term is a subtype of PPROM that occurs in 23-31 weeks and 6 days of pregnancy. Generally, PPROM has many maternal and fetal adverse effects. PPROM accounts for $30-40 \%$ of preterm births and is an independent risk factor for neonatal morbidity and mortality resulting from prematurity, respiratory distress syndrome (RDS), intraventricular hemorrhage, sepsis, and pulmonary hypoplasia [1]. In the long term, there is a risk of developing neurological sequelae (cerebral palsy) and lung disease (bronchopulmonary dysplasia) [2]. Since neonatal complications increase significantly in deliveries below 32 weeks, prolonging the gestational period is preferred in appropriate cases to decrease neonatal mortality and morbidity. Despite treatment, $50-60 \%$ of women with PPROM remote from term deliver within a week after the rupture of membrane [3].

Maternal risks also exist in the presence of PPROM and its subtype. The most important risk factor is clinical chorioamnionitis; the frequency of chorioamnionitis in PPROM 
or spontaneous preterm births has been reported to be 40-70\% [4]. Clinical chorioamnionitis also causes bleeding secondary to uterine atony, uterine rupture, endometritis, pelvic abscess, maternal sepsis, and an increase in the need for intensive care [5-7].

The most common source of the development of chorioamnionitis is the formation of fetal vessels (choriovasculitis) and inflammation of the amnion membrane (amnionitis) as a result of the change of normal flora in the lower genital tract and the increase in the number of pathogenic bacteria. This leads to the formation of prostaglandin, matrix metalloprotease and reactive oxygen radicals in maternal tissues after a while [8]. Maternal and fetal systemic inflammation also occurs in chorioamnionitis $[9,10]$. Cytokine increase in fetal blood initiates white matter necrosis in the brain. Fetal inflammatory response syndrome (FIRS) causes neurological sequelae in the long term [11]. It is thought that the main cause of neonatal morbidity is FIRS [12].

Antibiotic use in PPROM is associated with the prevention of clinical chorioamnionitis, prolongation of the latent phase, and reduction of neonatal and maternal morbidity $[13,14]$. However, antibiotics used in the treatment of chorioamnionitis also have a detrimental effect on the normal flora of the lower genital tract. This is especially the case when broad-spectrum antibiotics are used in treatment $[15,16]$. Normally, Lactobacillus spp. species in vaginal microflora constitute the most important barrier against the development of infection. Vaginal infections developing during pregnancy are successfully treated with locally applied probiotics [17]. A previous study showed that vaginal probiotics administered synchronously with antibiotic treatment prolong the latent phase significantly and positively affect neonatal outcomes in PPROM cases remote from term [18].

This study aims to examine the perinatal effects of the antibiotic + vaginal probiotic treatment used in PPROM cases remote from term.

\section{MATERIAL AND METHODS}

The retrospective study was conducted by evaluating the results of expectant treatment applied to patients hospitalized with the diagnosis of PPROM remote from term (cases with 23 weeks and 31 weeks and 6 days of pregnancy) in the Obstetrics Service of Firat University Faculty of Medicine, Department of Obstetrics and Gynecology between January 2019 and January 2021. The study was initiated after the approval of the local ethics committee (Ethics committee approval number: 2019-01/25). Patients with a pregnancy between 23 weeks and 31 weeks and six days at the time of diagnosis and those in whom the period between the date of hospitalization and the date of birth (latent phase) was 14 days or more were included in the study. Through the examination of the files, the age, obstetric history and characteristics of the pregnancy were recorded. Patients who were in active labor at the time of admission, who experienced clinical signs of chorioamnionitis [fever, uterine fundal tenderness, maternal tachycardia (> 100/min), fetal tachycardia (> 160/min) and purulent amniotic fluid], who had fetal distress and/or significant vaginal bleeding as well as those with other obstetric risk factors such as pregnancy-induced hypertension, gestational diabetes, fetal anomaly, and multiple pregnancies were excluded from the study.

The records regarding ultrasonography performed for the confirmation of gestational age and evaluation of amniotic fluid volume were examined and fetal results were recorded. In the treatment plan, the white blood cell and lymphocyte count and $C$ reactive protein (CRP) values in theblood valuesobtainedfrom the patientswere recorded.The values at the time of delivery and the values at the time of admission were recorded.

As the standard treatment protocol, Ampicillin $1 \mathrm{~g}$ flc. $4 \times 1 /$ day (Ampisina $1 \mathrm{~g}$. flc., Mustafa Nevzat Pharmaceuticals Istanbul, Turkey) and vaginal $1 \times 1$ /day of Lactobacillus casei rhamnosus (> 40000 CFU) (Vagiflor vaginal capsule, Paris, France) were given to all patients until delivery. Antibiotic treatment was continued for three weeks and discontinued for one week. In this way, it was continued until birth. Lactobacillus casei rhamnosus treatment was continued until delivery. Magnesium sulphate IV was initiated for fetal neuroprotection in cases with a pregnancy between 23-31 weeks and six days among the cases decided to give birth [19]. As the clinical criteria of chorioamnionitis, the key clinical finding associated with clinical chorioamnionitis was accepted as having at least two of the following symptoms: fever, uterine fundal tenderness, maternal tachycardia (> 100/min), fetal tachycardia (> 160/min), and purulent or foul amniotic fluid [20]. In those who developed clinical chorioamnionitis, broad spectrum antibiotics that were effective against Gram-positive and Gram-negative microorganisms were initiated.

The patients were divided into two as Group 1 who did not develop chorioamnionitis during the treatment and Group 2 who developed clinical findings of chorioamnionitis during the treatment. In both groups, gestational age during delivery, the latent period, birth weight, and the 5-minute APGAR score after birth were obtained from the records. Neonatal complications such as neonatal sepsis, respiratory distress syndrome (RDS), pulmonary hypoplasia, pneumonia and necrotizing enterocolitis (NEC), retinopathy of prematurity, and perinatal mortality data were obtained from the records of the neonatal unit. 


\section{Statistical analysis}

Statistical Package for the Social Sciences 21.0 statistics software was used for statistical analysis of the data. Within group evaluations, the normality tests of continuous variables were performed using the Kolmogorov Smirnov test. The Paired Samples t-test was used to compare normally distributed continuous variables, while the Related Sample Wilcoxon Signed Rank Test was used to compare continuous variables which were not normally distributed. While comparing the within-group mean measurement of continuous variables in the group with $\mathrm{n}<30$, the Related Sample Wilcoxon Sign Rank test was used again.

The Repeated Measures ANOVA method was used to test whether two different measurements of continuous variables belonging to the same group changed due to a factor. The Mann Whitney $U$ test was used to compare continuous variables between the two groups. The Shapiro Wilk Test was applied to determine whether the data were normally distributed. $\mathrm{p}<0.05$ was considered statistically significant.

\section{RESULTS}

During the period, 2829 deliveries were conducted in the obstetrics service. Preterm PROM was detected in 321 cases $(11.34 \%)$, and PPROM remote from term was diagnosed in 97 cases. The incidence of PROM remote from term was calculated as $3.42 \%$ (1/29). In 51 cases, the latent phase lasted less than 14 days. Twelve of these cases were in activation at the time of diagnosis. Nine showed clinical signs of chorioamnionitis. Thirty cases gave birth between
2 and 13 days after diagnosis. In the cases who received Ampicilin + L. casei rhamnosus treatment, the cases (46 cases) whose latent phase was 14 days, or more were found to be $60.5 \%$.

Clinical chorioamnionitis developed in 6 (13.04\%) of the 46 pregnant women included in the study. Accordingly, 40 cases without clinical chorioamnionitis were determined as Group 1 while six cases with clinical chorioamnionitis were accepted as Group 2. The patients were delivered in those who developed clinical findings of chorioamnionitis. Other cases were terminated in the gestational age of maximum 34 weeks 0 days depending on obstetric indications. In both groups, cesarean section (C/S) was performed with obstetric indications, and C/S ratio was 30\% in Group 1 whereas it was $83.3 \%$ in Group 2. Additionally, in Group 2, two cases were taken to $C / S$ due to previous $C / S$, one case due to breech presentation, one case due to cord prolapse, and one case due to fetal dysterosis. Surgical site infection developed in three cases (7.5\%) who underwent C/S in Group 1, while it occurred in one case (16.6\%) in Group 2. Maternal mortality and permanent morbidity were not seen in either group.

In Group 1 ( $\mathrm{n}: 40$ ), obstetric characteristics and laboratory data at the time of diagnosis and delivery are presented in Table 1. The mean gestational age at the time of diagnosis was $28.43 \pm 2.38$ while the mean gestational age at the time of delivery was $32.38 \pm 2.07$ (mean latent time: $27.45 \pm 1.71$ days). In this group, $\mathrm{Hb}$ and $\mathrm{Htc}$ values decreased significantly as the pregnancy progressed. There was no statistically significant difference between the time

\begin{tabular}{|c|c|c|c|c|c|c|c|}
\hline Group 1 & Parameters & Mean & SD & Difference & $\begin{array}{l}\text { Proportional } \\
\text { Difference }\end{array}$ & p correlation & $p$ value \\
\hline \multirow{2}{*}{$\begin{array}{l}\text { GW } \\
\text { [week] }\end{array}$} & Admission & 28.43 & 2.38 & \multirow{2}{*}{3.950} & \multirow{2}{*}{$13.9 \%$} & \multirow{2}{*}{0.000} & \multirow{2}{*}{$0.000^{* *}$} \\
\hline & Delivery & 32.38 & 2.07 & & & & \\
\hline \multirow{2}{*}{$\begin{array}{l}\text { WBC } \\
{\left[10 \mathrm{e}^{3} / \mu \mathrm{L}\right]}\end{array}$} & Admission & 12332.00 & 3568.49 & \multirow{2}{*}{102.750} & \multirow{2}{*}{$0.8 \%$} & \multirow{2}{*}{0.706} & \multirow{2}{*}{$0.883^{*}$} \\
\hline & Delivery & 12434.75 & 2749.55 & & & & \\
\hline \multirow{2}{*}{$\begin{array}{l}\mathrm{Hb} \\
{[\mathrm{g} / \mathrm{dL}]}\end{array}$} & Admission & 11.55 & 1.37 & \multirow{2}{*}{-0.878} & \multirow{2}{*}{$-7.6 \%$} & \multirow{2}{*}{0.000} & \multirow{2}{*}{$0.000^{*}$} \\
\hline & Delivery & 10.67 & 1.48 & & & & \\
\hline \multirow{2}{*}{$\begin{array}{l}\mathrm{Htc} \\
{[\%]}\end{array}$} & Admission & 34.96 & 4.32 & \multirow{2}{*}{-2.617} & \multirow{2}{*}{$-7.5 \%$} & \multirow{2}{*}{0.001} & \multirow{2}{*}{$0.000^{*}$} \\
\hline & Delivery & 32.34 & 4.37 & & & & \\
\hline \multirow{2}{*}{$\begin{array}{l}\text { Plt } \\
{[10 \mathrm{e} 3 / \mu \mathrm{L}]}\end{array}$} & Admission & 274.33 & 79.51 & \multirow{2}{*}{-11.125} & \multirow{2}{*}{$-4.1 \%$} & \multirow{2}{*}{0.000} & \multirow{2}{*}{$0.221^{*}$} \\
\hline & Delivery & 263.20 & 77.06 & & & & \\
\hline \multirow{2}{*}{$\begin{array}{l}\text { Lymphocyte } \\
{[10 \mathrm{e} 3 / \mu \mathrm{L}]}\end{array}$} & Admission & 1.57 & 0.51 & \multirow{2}{*}{0.076} & \multirow{2}{*}{$4.9 \%$} & \multirow{2}{*}{0.191} & \multirow{2}{*}{$0.478^{*}$} \\
\hline & Delivery & 1.64 & 0.56 & & & & \\
\hline \multirow{2}{*}{$\begin{array}{l}\text { CRP } \\
{[\mathrm{mg} / \mathrm{L}]}\end{array}$} & Admission & 7.39 & 5.55 & \multirow{2}{*}{0.704} & \multirow{2}{*}{$9.5 \%$} & \multirow{2}{*}{0.002} & \multirow{2}{*}{$0.657^{* *}$} \\
\hline & Delivery & 8.10 & 5.60 & & & & \\
\hline
\end{tabular}

* — paired t test; ${ }^{* *}$ — related Sample Wilcoxon Signed Rank test; CRP — C reactive protein; $\mathrm{Hb}$ - hemoglobin; Htc — hematocrit; SD — standard deviation; Plt — platelet; WBC — white blood cell; GW — gestational weeks 


\begin{tabular}{|c|c|c|c|c|c|c|c|}
\hline Group 2 & Parameters & Mean & SD & Difference & $\begin{array}{l}\text { Proportional } \\
\text { Difference }\end{array}$ & p correlation & p value ${ }^{* *}$ \\
\hline \multirow{2}{*}{$\begin{array}{l}\text { GW } \\
\text { [week] }\end{array}$} & Admission & 28.17 & 1.33 & \multirow{2}{*}{3.167} & \multirow{2}{*}{$11.2 \%$} & \multirow{2}{*}{0.395} & \multirow{2}{*}{0.026} \\
\hline & Delivery & 31.33 & 1.63 & & & & \\
\hline \multirow{2}{*}{$\begin{array}{l}\text { WBC } \\
{\left[10 \mathrm{e}^{3} / \mu \mathrm{L}\right]}\end{array}$} & Admission & 12066.67 & 3616.44 & \multirow{2}{*}{800.000} & \multirow{2}{*}{$6.6 \%$} & \multirow{2}{*}{0.097} & \multirow{2}{*}{0.345} \\
\hline & Delivery & 12866.67 & 4175.00 & & & & \\
\hline \multirow{2}{*}{$\begin{array}{l}\mathrm{Hb} \\
{[\mathrm{g} / \mathrm{dL}]}\end{array}$} & Admission & 11.13 & 0.87 & \multirow{2}{*}{-1.283} & \multirow{2}{*}{$-11.5 \%$} & \multirow{2}{*}{0.064} & \multirow{2}{*}{0.043} \\
\hline & Delivery & 9.85 & 1.14 & & & & \\
\hline \multirow{2}{*}{$\begin{array}{l}\mathrm{Htc} \\
{[\%]}\end{array}$} & Admission & 33.65 & 2.54 & \multirow{2}{*}{-3.950} & \multirow{2}{*}{$-11.7 \%$} & \multirow{2}{*}{0.114} & \multirow{2}{*}{0.028} \\
\hline & Delivery & 29.70 & 3.53 & & & & \\
\hline \multirow{2}{*}{$\begin{array}{l}\text { Plt } \\
{[10 \mathrm{e} 3 / \mu \mathrm{L}]}\end{array}$} & Admission & 299.17 & 111.72 & \multirow{2}{*}{60.333} & \multirow{2}{*}{$20.2 \%$} & \multirow{2}{*}{0.096} & \multirow{2}{*}{0.249} \\
\hline & Delivery & 359.50 & 144.58 & & & & \\
\hline \multirow{2}{*}{$\begin{array}{l}\text { Lymphocyte } \\
{[10 \mathrm{e} 3 / \mu \mathrm{L}]}\end{array}$} & Admission & 1.65 & 0.74 & \multirow{2}{*}{0.217} & \multirow{2}{*}{$13.1 \%$} & \multirow{2}{*}{0.145} & \multirow{2}{*}{0.357} \\
\hline & Delivery & 1.87 & 0.19 & & & & \\
\hline \multirow{2}{*}{$\begin{array}{l}\text { CRP } \\
{[\mathrm{mg} / \mathrm{L}]}\end{array}$} & Admission & 8.00 & 5.54 & \multirow{2}{*}{110.167} & \multirow{2}{*}{$1377.1 \%$} & \multirow{2}{*}{0.445} & \multirow{2}{*}{0.028} \\
\hline & Delivery & 118.17 & 54.80 & & & & \\
\hline
\end{tabular}

** — related Sample Wilcoxon Signed Rank test; CRP — C reactive protein; $\mathrm{Hb}$ - hemoglobin; Htc — hematocrit; SD — standard deviation; PIt — platelet; WBC — white blood cell; GW - gestational weeks

of diagnosis and the time of birth in lymphocyte (Paired t test) and CRP (Related Sample Wilcoxon Signed Rank test), levels ( $p>0.05)$.

Obstetric characteristics and laboratory data of Group 2 ( $n: 6$ ) at the time of diagnosis and delivery are given in Table 2, and the mean gestational age at the time of diagnosis was $28.17 \pm 1.33$ and the mean gestational age at the time of delivery was found to be $31.33 \pm 1.63$ (mean latent time: $23.66 \pm 4.53$ days). In this group, $\mathrm{Hb}$ (Related Sample Wilcoxon Signed Rank test) and Htc (Related Sample Wilcoxon Signed Rank test) values showed a significant decrease as the pregnancy progressed $(p<0.05)$. The patients were delivered in one case on the $40^{\text {th }}$ day after admission to the hospital, two on the $27^{\text {th }}$ day, one on the $20^{\text {th }}$ day, and two on the $14^{\text {th }}$ day as clinical chorioamnionitis developed. In Group 2, there was a 20.2\% increase between Plt. (Related Sample Wilcoxon Signed Rank test) values at the time of diagnosis and the time of delivery. This increase was not statistically significant $(p>0.05)$. While there was no significant difference between lymphocyte (Related Sample Wilcoxon Signed Rank test) levels in Group 2, when CRP (Related Sample Wilcoxon Signed Rank test) levels were examined, a statistically significant difference was found between the time of diagnosis and the moment of birth $(p<0.05)$.

When obstetric characteristics and neonatal parameters of the pregnant women were compared for Group 1 and Group 2, it was found that the results were similar. The 5-minute APGAR score was higher in Group 1 and that result was statistically significant in Group 1 ( $p<0.05$, Mann Whitney $\mathrm{U}$ test.). Values are given in Table 3 .
Table 3. Obstetric characteristics and neonatal parameters of pregnant women

\begin{tabular}{|l|l|l|l|}
\hline Parameters & $\begin{array}{l}\text { Group 1 }(\mathbf{n : ~ 4 0 )} \\
\text { Mean } \pm \text { SD }\end{array}$ & $\begin{array}{l}\text { Group 2 }(\mathbf{n : ~} \mathbf{6}) \\
\text { Mean } \pm \text { SD }\end{array}$ & p value* \\
\hline Age [year] & $29.27 \pm 0.96$ & $26.83 \pm 1.37$ & NS \\
\hline GW admission & $28.42 \pm 0.37$ & $28.16 \pm 0.54$ & NS \\
\hline GW delivery & $32.37 \pm 0.37$ & $31.33 \pm 0.66$ & NS \\
\hline $\begin{array}{l}\text { Latent phase } \\
\text { [day] }\end{array}$ & $27.45 \pm 1.71$ & $23.60 \pm 4.53$ & NS \\
\hline $\begin{array}{l}\text { Newborn } \\
\text { weight [gram] }\end{array}$ & $1965.87 \pm 86.46$ & $1700 \pm 145.27$ & NS \\
\hline $\begin{array}{l}\text { APGAR Score } \\
5^{\text {th }} \text { minute }\end{array}$ & $8.55 \pm 0.17$ & $5.83 \pm 0.087$ & 0.003 \\
\hline
\end{tabular}

* - Mann Whitney U test; GA — gestational age; SD — standard deviation; GW - gestational weeks; NS — not significant

\section{When neonatal parameters are examined}

Sepsis developed in six newborns in Group 1 (15\%, within group \%). Two newborns who developed sepsis died while four newborns were discharged. When sepsis factors were examined, it was seen that Staph. Aureus grew in one newborn, Staph. Epidermidis in two newborns, Strep. Viridans in a newborn and although a newborn showed signs of sepsis, there was no reproduction in repeated cultures. Records of a newborn referred to another hospital with a pre-diagnosis of sepsis were not available. In Group 1, a total of four newborns died (10\%, within group \%). Two $(5 \%$, within group \%) died due to sepsis. One of the two newborns who died due to sepsis was born at 27 weeks 
and 1 day with abdominal bleeding due to placenta previa totalis, and the baby died on the $11^{\text {th }}$ day due to sepsis. The second newborn was born at 30 weeks and 2 days (uterine anomaly, breech delivery could not be stopped), and died on the $63^{\text {rd }}$ day due to sepsis. In the third newborn who died, the latent phase was determined as 26 days and was delivered at 32 weeks and 2 days upon the development of severe preeclampsia. The baby died on the second postnatal day due to the development of tension pneumothorax and gastrointestinal bleeding. The $4^{\text {th }}$ newborn was born in the 30th week of gestation and died on the postnatal $2^{\text {nd }}$ day due to prematurity and respiratory failure. Congenital hypothyroidism and amniotic band syndrome were diagnosed in a newborn who developed PPROM at the $28^{\text {th }}$ week of gestation and gave birth at the $32^{\text {nd }}$ week and $2^{\text {nd }}$ day (latent phase 30 days). In this group, intrauterine growth retardation (IUGR) was diagnosed in five fetuses $(12.5 \%$, within the group). Prematurity retinopathy (ROP) developed in five newborns in Group 1 (12.5\%, within group \%). All newborns who developed ROP were discharged.

Six cases with clinical chorioamnionitis were detected in Group 2, three of the newborns developed sepsis (50\%, within the group $\%$ ) and two babies (33.3\%, within the group $\%)$ died due to sepsis. Considering sepsis factors, it was seen that Streptococcus spp. grew in one newborn, Acinetobacter in one newborn, and Staph. epidermidis in one newborn. The birth week of one of the newborns who died was determined as 30 weeks and 2 days, and the baby died on the postnatal $2^{\text {nd }}$ day. The birth week of the other newborn was determined as 29 weeks and 3 days and died from sepsis on the $36^{\text {th }}$ day. While one of the babies who died was diagnosed with sepsis and pulmonary hypertension, there was no pathology other than sepsis in the others. A newborn with sepsis was successfully discharged. Amniotic band syndrome and pyloric stenosis were diagnosed in a newborn. Premature retinopathy (ROP) developed in two newborns (33.3\%, within group\%). All newborns who developed ROP were discharged. In the first group, five fetuses (12.5\%) developed intrauterine growth retardation (IUGR), while there was no such diagnosis in the second group. Newborns are accepted as Small for gestational age (SGA). While respiratory distress syndrome developed in three cases (7.5\%) in Group 1, it developed in two cases (33.3\%) in Group 2. Amniotic band syndrome was diagnosed in one newborn in both groups ( $2.5 \%$ and $16.6 \%$, respectively). Neonatal results of both groups are given in Table 4.

\section{DISCUSSION}

Etiology of PPROM is multifactorial. Expectant treatment is conventionally applied in cases of uncomplicated rupture of membranes that develop less than 34 weeks. For this purpose, antibiotics, corticosteroids, magnesium sulfate,

\begin{tabular}{|l|l|l|}
\hline \multicolumn{3}{|l|}{ Table 4. Neonatal results of Group 1 and Group 2} \\
\hline Newborn Results & $\begin{array}{l}\text { Group } \mathbf{1}(\%) \\
\text { n: } 40\end{array}$ & $\begin{array}{l}\text { Group 2 (\%) } \\
\text { n: } 6\end{array}$ \\
\hline Discharged & $36(90)$ & $4(66.7)$ \\
\hline Died & $4(10)$ & $2(33.3)$ \\
\hline Sepsis developed & $6(15)$ & $3(50)$ \\
\hline Death due to sepsis & $2(5)$ & $2(33.3)$ \\
\hline ROP & $5(12.5)$ & $2(33.3)$ \\
\hline ABS & $1(2.5)$ & $1(16.6)$ \\
\hline SGA & $5(12.5)$ & - \\
\hline RDS & $7(17.5)$ & $3(50.0)$ \\
\hline
\end{tabular}

ABS - amniotic band syndrome; $\mathrm{n}$ - number; RDS - respiratory distress syndrome; ROP — retinopathy of prematurity; SGA — small for gestational age

and tocolytics are used. While antibiotics are given to prevent the development of morbidity due to chorioamnionitis and neonatal infection and to prolong the latent phase, the others are used to reduce adverse neonatal outcomes [21-23].

Chorioamnionitis is one of the main causes of maternal and neonatal morbidity. The incidence of chorioamnionitis is inversely proportional to gestational age. Its frequency is $41 \%$ in births before 27 weeks, while it is $15 \%$ in births between 28-36 weeks [24]. Chorioamnionitis can occur clinically, subclinically or histologically. Unlike histological chorioamnionitis, the negative effects of clinical chorioamnionitis on the newborn are more pronounced [25]. In a study conducted by Nasef et al. [26], it was shown that histological chorioamnionitis had no effect on neonatal morbidity and neurodevelopmental disorders.

Unfortunately, there is no objective diagnosis of clinical chorioamnionitis. The most important parameter in diagnosis is maternal fever $\left(38^{\circ} \mathrm{C}\right.$ and above) [20]. Maternal leukocytosis white blood cell (WBC) over 15,000 alone is not a definitive feature for diagnosis [27]. When clinical chorioamnionitis is suspected, other reasons explaining fever should be excluded [28]. When a clinical diagnosis of chorioamnionitis is made due to adverse maternal and fetal effects, delivery should be planned regardless of the gestational age [29]. In our study, the frequency of clinical chorioamnionitis was found to be $13.0 \%$ ( 6 cases). After the diagnosis, the pregnancies of these cases were terminated. The type of delivery was determined by obstetric indications, and permanent maternal morbidity did not develop.

Some recent studies examining PPROM cases remote from term have shown a significant improvement in perinatal outcomes with the use of vaginal probiotics in addition to standard antibiotic treatment $[18,30]$.Vaginal probiotics containing lactobacilli are the most widely used probiotic group. Lactobacilli decrease vaginal $\mathrm{pH}$ by producing lactic acid, produce antibacterial agents and stimulate the immune system by producing anti-inflammatory cytokines 
[31-33]. Probiotics can be used safely in any period of pregnancy [34].

Infection development is an important problem in PPROM cases. In a study, the frequency of intrauterine infection was found to be $60 \%$ in cases where antibiotics were not used after membrane rupture, due to ascending bacterial invasion [3]. In PROM cases remote from term, for whom Bendix et al. applied expectant treatment, $45 \%$ of the major complications developed due to chorioamnionitis [35]. In another study, 1153 PPROM cases with 24-34 weeks of gestation were examined retrospectively, and the frequency of clinical chorioamnionitis was found to be $29 \%$ [36]. In our study, the frequency of clinical chorioamnionitis was found to be $13.0 \%$. The use of a probiotic agent as a treatment has been found to be effective in reducing clinical rates of chorioamnionitis.

In the study of Aziz et al. [36], newborns born to mothers with PPROM diagnosed with clinical chorioamnionitis were found to have higher ( $34.8 \%$ vs $22.9 \%$ ) RDS, necrotizing enterocolitis, intracranial hemorrhage, pneumonia, and low 5-minute APGAR scores compared to newborns born to mothers without chorioamnionitis. In the study, the frequency of neonatal sepsis in the group developing chorioamnionitis was $7.1 \%$ while it was $5.6 \%$ for the other group. The low 5-minute APGAR score was found to be $34 \%$ versus $23 \%$. In our study, the frequency of neonatal sepsis in the group developing chorioamnionitis was $50 \%$ versus $15 \%$, the low 5-minute APGAR score was found to be $50 \%$ versus $5 \%$, and the frequency of RDS was $33.3 \%$ vs $7.5 \%$. Since our study evaluated cases with latent phase longer than 14 days, we think that sepsis rates were higher.

Approximately $75 \%$ of cases developing midtrimester PPROM give birth within 15 days [37]. Therefore, we examined cases in which the latent phase was at least 14 days. With the antibiotic + probiotic treatment applied during the expectant treatment, the mean latent phase was 27.4 days in Group 1, whereas it was 23.6 days in Group 2. We think that fetal weights were positively affected in both groups due to the positive contribution of the treatment on the latent phase. The mean weight of the babies in Group 1 was $1965.87 \pm 86.46 \mathrm{~g}$. and $1700 \pm 145.27 \mathrm{~g}$. in Group 2 . Newborn weights were not statistically significant between both groups. However, SGA was detected in five newborns in Group 1.

In our study, $66.7 \%$ of the newborns in the group developing clinical chorioamnionitis were discharged healthily from the hospital, while this rate was found to be $90 \%$ in the group without chorioamnionitis. Considering Group 2 and Group 1, respectively, neonatal mortality was 33.3\% versus $10 \%$, ROP was $33.3 \%$ versus $12.5 \%$, and amniotic band syndrome was $16.6 \%$ vs $2.5 \%$. We think that the prolongation of the latent phase positively affects neonatal outcomes in both groups. In our study, no cases of intracranial hemorrhage and necrotizing enterocolitis were found in either group.

\section{CONCLUSIONS}

Ampicillin + Lactobacillus casei rhamnosus is an effective treatment method in PPROM cases and positively affects perinatal outcomes. The limitation of our study is that it is retrospective, and the number of cases is relatively low. In addition, long-term neurological results in newborns could not be examined. There is a need for larger scale studies on the issue.

\section{Ethics committee approval}

Firat University Faculty of Medicine Ethics Review Committee approved the trial (reference number 2019-01/25).

\section{Financial disclosure}

Author has any financial or commercial affiliation with this study.

\section{Conflict of interest}

There are no conflicts of interest to declare.

\section{REFERENCES}

1. Ugwumadu A. Chapter 20 - Preterm Prelabour Rupture of Membranes (pPROM). In: Sir Arulkumaran A. ed. Best Practice in Labour and Delivery 2nd edition. Cambridge University Press 2016: 242-249.

2. Henriquez GG, Rodrigo FGM. Chorioamnionitis and neonatal morbidity: current perspectives. Res Rep Neonatol. 2017; Volume 7: 41-52, doi: 10.2147/rrn.s128751.

3. Mercer B. Preterm premature rupture of the membranes. Obstet Gynecol. 2003; 101(1): 178-193, doi: 10.1016/s0029-7844(02)02366-9, indexed in Pubmed: 12517665 .

4. Yoon $\mathrm{BH}$, Romero $\mathrm{R}$, Moon JB, et al. Clinical significance of intra-amniotic inflammation in patients with preterm labor and intact membranes. Am J Obstet Gynecol. 2001; 185(5): 1130-1136, doi: 10.1067/mob.2001.117680, indexed in Pubmed: 11717646.

5. Rouse DJ, Landon M, Leveno KJ, et al. The Maternal-Fetal Medicine Units cesarean registry: chorioamnionitis at term and its duration-relationship to outcomes. Am J Obstet Gynecol. 2004; 191(1): 211-216, doi: 10.1016/j. ajog.2004.03.003, indexed in Pubmed: 15295368.

6. Perry AK, Rossi RM, DeFranco EA. Severe adverse maternal outcomes associated with chorioamnionitis. Am J Obstet Gynecol MFM. 2019; 1(3): 100027, doi: 10.1016/j.ajogmf.2019.06.006, indexed in Pubmed: 33345791.

7. Venkatesh KK, Glover AV, Vladutiu CJ, et al. Association of chorioamnionitis and its duration with adverse maternal outcomes by mode of delivery: a cohort study. BJOG. 2019; 126(6): 719-727, doi: 10.1111/14710528.15565, indexed in Pubmed: 30485648.

8. Romero R, Mazor M. Infection and preterm labor. Clin Obstet Gynecol. 1988;31(3): 553-584, doi: 10.1097/00003081-198809000-00006, indexed in Pubmed: 3066544.

9. Galaz J, Romero R, Slutsky R, et al. Cellular immune responses in amniotic fluid of women with preterm prelabor rupture of membranes. J Perinat Med. 2020; 48(3): 222-233, doi: 10.1515/jpm-2019-0395, indexed in Pubmed: 32083453.

10. Romero R, Chaemsaithong P, Korzeniewski SJ, et al. Clinical chorioamnionitis at term II: the intra-amniotic inflammatory response. J Perinat Med. 2016; 44(1): 5-22, doi: 10.1515/jpm-2015-0045, indexed in Pubmed: 25938217.

11. Shalak LF, Laptook AR, Jafri HS, et al. Clinical chorioamnionitis, elevated cytokines, and brain injury in term infants. Pediatrics. 2002; 110(4): 673-680, doi: 10.1542/peds.110.4.673, indexed in Pubmed: 12359779. 
12. Arad I, Ergaz Z. The fetal inflammatory response syndrome and associated infant morbidity. Isr Med Assoc J. 2004; 6(12): 766-769, indexed in Pubmed: 15609892

13. Kenyon S, Boulvain M, Neilson JP. Antibiotics for preterm rupture of membranes. Cochrane Database Syst Rev. 2013(12): CD001058, doi: 10.1002/14651858.CD001058.pub3, indexed in Pubmed: 24297389.

14. Oboro VO, Adekanle BA, Apantaku BD, et al. Pre-term pre-labour rupture of membranes: effect of chorioamnionitis on overall neonatal outcome. J Obstet Gynaecol. 2006; 26(8): 740-743, doi: 10.1080/01443610600955776, indexed in Pubmed: 17130019.

15. Blackwell SC, Berry SM. Role of amniocentesis for the diagnosis of subclinical intra-amniotic infection in preterm premature rupture of the membranes. Curr Opin Obstet Gynecol. 1999; 11(6): 541-547, doi: 10.1097/00001703-199912000-00001, indexed in Pubmed: 10674829.

16. Kyle $P$, Turner DP. Chorioamnionitis due to pseudomonas aeruginosa: a complication of prolonged antibiotic therapy for premature rupture of membranes. Br J Obstet Gynaecol. 1996; 103(2): 181-183, doi: 10.1111/j.1471-0528.1996.tb09675.x, indexed in Pubmed: 8616140.

17. Othman $M$, Neilson JP, Alfirevic Z. Probiotics for preventing preterm labour. Cochrane Database Syst Rev. 2007(1), doi: 10.1002/14651858. CD005941.pub2, indexed in Pubmed: 17253567.

18. Kavak SB, Kavak E, Ilhan R, et al. The efficacy of ampicillin and Lactobacillus casei rhamnosus in the active management of preterm premature rupture of membranes remote from term. Drug Des Devel Ther. 2014; 8: 1169-1173, doi: 10.2147/DDDT.S68552, indexed in Pubmed: 25210439.

19. American College of Obstetricians and Gynecologists' Committee on Practice Bulletins-Obstetrics. Practice Bulletin No. 171: Management of Preterm Labor. Obstet Gynecol. 2016; 128(4): e155-e164, doi: 10.1097/AOG.0000000000001711, indexed in Pubmed: 27661654.

20. Newton ER. Preterm labor, preterm premature rupture of membranes, and chorioamnionitis. Clin Perinatol. 2005; 32(3): 571-600, doi: 10.1016/j. clp.2005.05.001, indexed in Pubmed: 16085021

21. Yudin M, Schalkwyk Jv, Eyk N, et al. Antibiotic Therapy in Preterm Premature Rupture of the Membranes. J Obstet Gynaecol Can. 2009; 31(9): 863-867, doi: 10.1016/s1701-2163(16)34305-5, indexed in Pubmed: 19941711.

22. Fox NS, Gelber SE, Kalish RB, et al. The recommendation for bed rest in the setting of arrested preterm labor and premature rupture of membranes. Am J Obstet Gynecol. 2009; 200(2): 165.e1-165.e6, doi: 10.1016/j. ajog.2008.08.007, indexed in Pubmed: 19019329.

23. Rouse DJ, Hirtz DG, Thom E, et al. A randomized, controlled trial of magnesium sulfate for the prevention of cerebral palsy. N Engl J Med. 2008; 359(9): 895-905, doi: 10.1056/NEJMoa0801187, indexed in Pubmed: 18753646

24. Newton ER. Chorioamnionitis and intraamniotic infection. Clin Obstet Gynecol. 1993; 36(4): 795-808, doi: 10.1097/00003081-19931200000004, indexed in Pubmed: 8293582.

25. Botet $F$, Figueras J, Carbonell-Estrany $X$ et al. Effect of maternal clinical chorioamnionitis on neonatal morbidity in very-low birthweight infants: a case-control study. J Perinat Med. 2010; 38(3): 269-273, doi: 10.1515/jpm.2010.029, indexed in Pubmed: 20121532.
26. Nasef $N$, Shabaan $A E$, Schurr $P$, et al. Effect of clinical and histological chorioamnionitis on the outcome of preterm infants. Am J Perinatol. 2013; 30(1): 59-68, doi: 10.1055/s-0032-1321501, indexed in Pubmed: 22773280.

27. Shim SS, Romero R, Hong JS, et al. Clinical significance of intra-amniotic inflammation in patients with preterm premature rupture of membranes. Am J Obstet Gynecol. 2004; 191(4): 1339-1345, doi: 10.1016/j. ajog.2004.06.085, indexed in Pubmed: 15507963.

28. Morales WJ. The effect of chorioamnionitis on the developmental outcome of preterm infants at one year. Obstet Gynecol. 1987; 70(2): 183-186, indexed in Pubmed: 3601280

29. Conde-Agudelo A, Romero R, Jung EJ, et al. Management of clinica chorioamnionitis: an evidence-based approach. Am J Obstet Gynecol. 2020; 223(6): 848-869, doi: 10.1016/j.ajog.2020.09.044, indexed in Pubmed: 33007269 .

30. Daskalakis GJ, Karambelas AK. Vaginal Probiotic Administration in the Management of Preterm Premature Rupture of Membranes. Fetal Diagn Ther. 2017; 42(2): 92-98, doi: 10.1159/000450995, indexed in Pubmed: 27744438

31. O'Hanlon DE, Moench TR, Cone RA. Vaginal $\mathrm{pH}$ and microbicidal lactic acid when lactobacilli dominate the microbiota. PLoS One. 2013; 8(11): e80074, doi: 10.1371/journal.pone.0080074, indexed in Pubmed: 24223212

32. Hawes SE, Hillier SL, Benedetti J, et al. Hydrogen peroxide-producing lactobacilli and acquisition of vaginal infections. J Infect Dis. 1996; 174(5): 1058-1063, doi: 10.1093/infdis/174.5.1058, indexed in Pubmed: 8896509.

33. Yeganegi M, Watson CS, Martins A, et al. Effect of Lactobacillus rhamnosus GR-1 supernatant and fetal sex on lipopolysaccharide-induced cytokine and prostaglandin-regulating enzymes in human placental trophoblast cells: implications for treatment of bacterial vaginosis and prevention of preterm labor. Am J Obstet Gynecol. 2009; 200(5): 532.e1-532.e8, doi: 10.1016/j.ajog.2008.12.032, indexed in Pubmed: 19285652.

34. Dugoua JJ, Machado M, Zhu Xu, et al. Probiotic safety in pregnancy: a systematic review and meta-analysis of randomized controlled trials of Lactobacillus, Bifidobacterium, and Saccharomyces spp. J Obstet Gynaecol Can. 2009; 31(6): 542-552, doi: 10.1016/s1701-2163(16)34218-9, indexed in Pubmed: 19646321.

35. Bendix JM, Hegaard HK, Bergholt T, et al. Expectant management of PPROM and major complications before planned delivery: a retrospective cohort study. J Obstet Gynaecol. 2015; 35(6): 570-577, doi: 10.3109/01443615.2014.987114, indexed in Pubmed: 25517017.

36. Aziz N, Cheng YW, Caughey AB. Neonatal outcomes in the setting of preterm premature rupture of membranes complicated by chorioamnionitis. J Matern Fetal Neonatal Med. 2009; 22(9): 780-784, doi: 10.3109/14767050902922581, indexed in Pubmed: 19557664

37. Louis JM, Ehrenberg HM, Collin MF, et al. Perinatal intervention and neonatal outcomes near the limit of viability. Am J Obstet Gynecol. 2004; 191(4): 1398-1402, doi: 10.1016/j.ajog.2004.05.047, indexed in Pubmed: 15507972 